\title{
Economia Solidária: uma construção social e sua institucionalização
}

\author{
Economía Social: una construcción social y su institucionalización
}

Social Economy: a social construction and its institutionalization

\author{
Sandro da Silva ${ }^{1}$ \\ Angela Quintanilha Gomes ${ }^{2}$ \\ Davide Carbonai ${ }^{3}$
}

\begin{abstract}
Resumo
O presente trabalho pretende elucidar como o governo brasileiro a partir de 2003, após o fracasso das políticas neoliberais dos anos 1990, retomou a capacidade do enfrentamento das desigualdades sociais implementando políticas focalizadas e criando novas institucionalidades. Analisaremos com base nos documentos da Secretaria Nacional de Economia Solidária o caso da política pública de economia solidária implementada pelo governo federal brasileiro, que configura uma nova institucionalidade dentro de uma moldura de política distributiva. Utilizaremos a análise de conteúdo para examinar as características e objetivos atribuídos a política pública. Desta maneira foi possível verificar a existência de traços de outras molduras e que a nova institucionalidade derivou do poder de interferência construído pelo movimento, sendo uma política inovadora no que diz respeito ao processo decisório que delibera suas diretrizes e sua capacidade de articulação.
\end{abstract}

Palavras-Chave: economia solidária; política pública; governo.

\section{Resumen}

El presente trabajo desea clarificar cómo el gobierno brasileño desde 2003, después del fracaso de las políticas neoliberales de los años 1990, retomó la capacidad del enfrentamiento de las desigualdades sociales com la implemntación de políticas enfocadas y creando nuevas institucionalidads. Analizamos con base en los documientos de la Secretaría Nacional de Economía Solidaria el caso de la política pública de economía solidaria implementada por el gobierno federal brasileño, que es la configuración de una nueva institucionalidad dentro de un marco de política distributiva. Se utilizó el análisis de contenido para examinar las características y objetivos asignados a la política pública. De esta manera fue posible comprobar la existencia de rasgos de otros marcos y que la nueva institucionalidad derivó del poder de interferencia construido por el movimiento, siendo una política innovadora en lo que se refiere al proceso decisorio que delibera sus directrices y su capacidad de articulación.

Palabras claves: economía solidaria; política pública; gobierno.

1 Mestrando no Programa de Programa de Pós-Graduação em Políticas Públicas pela Universidade Federal do Pampa - UNIPAMPA - Campus São Borja, RS, Brasil. E-mail: sandro.cscp@gmail.com

${ }^{2}$ Doutora em Ciência Política. Professora Adjunta da Universidade Federal do Pampa - UNIPAMPA - Campus São Borja, RS, Brasil. E-mail:angelagomes@unipampa.edu.br.

${ }^{3}$ Doutor em Sociologia Econômica (Università di Teramo). Professor na Universidade Federal do Rio Grande do Sul (UFRGS), Porto Alegre, RS, Brasil. E-mail: davide.carbonai@gmail.com. 


\begin{abstract}
This paper intends to elucidate how the Brazilian government since 2003, after the failure of neoliberal policies of the 1990s, regained the capacity to face social inequalities by implementing focused policies and creating new institutionalism. Based on the Secretaria Nacional de Economia Solidária's documents, we will analyze the case of the public policy of social economy, implemented by the Brazilian federal government, which configures a new institutionalism within a framework of distributive politics. We will use the Qualitative Analysis of Content to examine features and objectives attributed to public policy. It was possible to verify the existence of elements of other frames and that the new institutionalism derived from the interference power built by the movement, being an innovative policy with respect to the decision-making process which deliberates its guidelines and networking capacity.
\end{abstract}

Keywords: social economy; public policy; government.

\title{
1. Introdução
}

As mudanças impostas pelo processo de globalização econômica remetem ao pensar a sociedade em definições globais. A globalização nada mais é que a conjunção de forças econômicas, políticas e ideológicas visando a ampliação econômica, isto significa construir uma hegemonia política global, que inclusive tem a capacidade de ser um agente influente na definição de políticas públicas que serão implementadas pelos Estados nacionais, Boneti (2011).

Este processo tem sua origem nos países desenvolvidos, que no pós-guerra com aplicação do conjunto de ideias keynesianas, atingiram elevados índices de produção e consumo em um contexto de pleno emprego. No entanto, a partir da década de 1970, com a crise do dólar e a diminuição das taxas de lucro, a situação se altera. Segundo Singer (1998), os lucros e os ganhos de produtividade eram pressionados pelos salários elevados, conquistados através da mobilização ao longo do tempo da classe operária. A resposta dos grandes industriais foi o deslocamento das linhas de produção para periferia que, detinha uma mão de obra barata em relação aos países desenvolvidos.

Os países da periferia não se encontravam no mesmo patamar dos países desenvolvidos, logicamente não portavam a mesma capacidade e competitividade no mercado internacional e foram pressionados a aplicar as medidas neoliberais que contêm como diretrizes, a retração das funções do Estado e a adoção de tecnologia no âmago do setor produtivo. Como efeitos deste processo observa-se a flexibilização dos processos de trabalho e o encolhimento dos postos de trabalho estrutural. Nos países periféricos, incluindo o Brasil, que atenuaram as desigualdades sociais.

No campo das políticas públicas conforme Souza (2006), que aponta a existência de uma reorientação das ações dos governos com relação aos gastos sociais, além das restrições de gastos, existe também uma diminuição da capacidade de intervenção do Estado. As 
políticas públicas que até então tinham um caráter universal, passam a ser focalizadas, sem que nenhum governo tenha conseguido encontrar uma fórmula para superar os problemas sociais presentes na América Latina.

É neste contexto que surgem movimentos sociais que questionam os efeitos causados pela globalização e as políticas neoliberais, além de atuarem no processo de redemocratização. Os movimentos sociais surgidos a partir da década de 1970 rompem com o paradigma clássico dos movimentos sociais, que tinham como proposta a ruptura da ordem societária vigente. Para Gohn (1997), os novos movimentos sociais têm como prerrogativas reivindicarem através de pautas específicas (questão da terra, meio ambiente e geração de trabalho e renda), e na medida em que existem pautas comuns assumem um caráter de transversalidade interagindo com outros atores coletivos, ampliando sua força de reivindicação e capacidade de intervenção na realidade.

Os movimentos sociais latino-americanos rompem com a velha esquerda e seus movimentos de libertação nacional, passando a ter seus projetos dentro da sociedade e não para sociedade. Não necessariamente almejam chegar ao poder estatal, porém lutam pela melhoria na qualidade de vida de grupos em vulnerabilidade social pautando transformações dentro da institucionalidade do Estado, como indica Bezerra (2014).

A economia solidária conforme Sanchez (2014), "re-surge" no cenário da redemocratização, no momento de fortalecimento dos movimentos sociais e se consolidam enquanto resistência ao neoliberalismo. A criação de empreendimentos coletivos e autogestionários configuram-se na reação dos trabalhadores a exclusão causada pelo receituário neoliberal, dos postos de trabalho formal nos anos 1980. Outro fator determinante segundo autor é o contexto político de rearticulação da sociedade civil e a emergência de novos atores na arena política, após mais de vinte anos sob governos autoritários, que restringiram direitos políticos e ausência de democracia.

O desgastado governo militar em virtude de suas medidas econômicas que levaram o país a uma crise sem precedentes, chega ao final na segunda metade da década de 1980. Com o movimento pelas "diretas já", a realização da eleição presidencial mesmo que de forma indireta em 1985 e a instalação da assembleia nacional constituinte, que culminou com a constituição de 1988, trouxeram novamente as perspectivas democráticas ao Brasil. A retomada da democracia significou, a lenta e gradual ampliação da participação da sociedade civil, bem como a criação de instituições sejam elas, de organização dos trabalhadores ou espaços públicos para proporcionar a inserção de atores na formulação de políticas públicas (Locks, 2014). 
Ainda que a nova constituição contenha em seu conteúdo perspectivas no âmbito dos direitos sociais, na atuação do Estado frente aos problemas sociais, o que se viu foi a instalação da agenda neoliberal nos governos brasileiros, nos anos 1990. O que significou diminuição da ação governamental no que se refere a políticas sociais. O enfoque das políticas públicas aplicadas no Brasil visou à estabilização econômica e a inserção do país no contexto globalizado. Os efeitos das políticas aplicadas resultaram em um aumento expressivo do desemprego e das desigualdades sociais como fica perceptível nos indicadores sociais do período. É possível notar através da figura que será exposta na sequencia que a um aumento progressivo do desemprego e da informalidade no país, ainda que se tratando da pobreza e da indigência os dados demonstrem uma redução. Durante a década de 1990, estes temas eram recorrentes na agenda pública de debates, sem que se tenha de fato aplicado medidas visando à solução dos problemas em evidência. De acordo com Loks (2014), atribui-se aos governos de Itamar Franco e Fernando Henrique Cardoso, o acanhamento quanto à elaboração de políticas sociais, período que compreende os anos de 1992 a 2002, que é marcado pela ausência de programas de impacto que fizessem frente aos problemas enfrentados.

\begin{tabular}{|l|c|c|c|c|c|c|c|}
\hline & 1992 & 1993 & 1995 & 1996 & 1997 & 1998 & 1999 \\
\hline Pobreza (\%) & 40,8 & 41,7 & 33,9 & 33,5 & 33,9 & 32,8 & 34,1 \\
\hline Indigência (\%) & 19,3 & 19,5 & 14,6 & 15,0 & 14,8 & 14,1 & 14,5 \\
\hline Desigualdades (Gini) & 0,590 & 0,602 & 0,599 & 0,600 & 0,600 & 0,598 & 0,592 \\
\hline Desemprego (\%) & 7,2 & 6,8 & 6,7 & 7,6 & 8,5 & 9,7 & 10,4 \\
\hline Informalidade (\%) & 39,9 & 40,9 & 42,6 & 43,2 & 43,4 & 43,9 & 45,7 \\
\hline
\end{tabular}

Figura 1 - Indicadores sociais dos anos 1990.

Fonte: LOKS, 2014.

No entanto, explicam Nagem; Silva (2013), que a medida adotada no período, enquanto tentativa de solução para estancar o desemprego, consistiu na criação do Fundo de Amparo ao Trabalhador (FAT) tendo em vista um Sistema Público de Emprego com suas ações centradas no tripé seguro-desemprego, qualificação profissional e intermediação de mão de obra, o que não foi capaz de conter o avanço dos índices.

Neste sentido ressalta Arretche (2002) apud Nagem; Silva (2013), que o processo de redemocratização trouxe consigo não apenas as eleições diretas, mas também uma transformação institucional no que tange a implementação de políticas públicas que 
passaram a ser aplicadas de forma descentralizada por entes federados subnacionais que receberam tal atribuição conforme a carta magna de 1988.

Conforme Gohn (2004), a década de 1990 no Brasil é marcada pelo enfraquecimento da capacidade de os movimentos sociais realizarem pressão demandando políticas sociais. Mas isto não quer dizer que desaparecem do cenário político, mas sim que se rearticulam e que outros atores ganham força.

Com advento do novo milênio e o fracasso da solução imposta aos países em desenvolvimento, líderes políticos latino-americanos que se colocaram em postura crítica ao neoliberalismo e seus efeitos durante a década de 1990, chegam ao poder. E como reações visam construir projetos alternativos ao vigente, na busca de retomar as soberanias nacionais e construir um modelo de desenvolvimento que enfatize as especificidades de cada território e população.

Com chegada de Luiz Inácio Lula da Silva a chefia da do Estado brasileiro, representa uma mudança da agenda pública brasileira. Porém a mudança de agenda não representa uma ruptura completa com os governos que o antecederam e com as mudanças nas capacidades de intervenção na realidade através do Estado, que teve sua capacidade reduzida pela adoção das políticas neoliberais. Dito isto, cabe refletir de que maneira um governo que elegeu-se opondo-se a agenda pública anterior considerada a causadora da atenuação dos problemas sociais, vai implementar estratégias que consigam imprimir de fato mudanças na realidade social e combater as desigualdades.

A estratégia política implementada teve como base a manutenção da política macroeconômica do governo anterior e a solução encontrada foi a implementação de políticas focalizadas e distributivas, e é isto que caracteriza a não ruptura total com modelo anterior. Para Borges (2010), a melhor estratégia é a implementação de políticas públicas, ou seja, uma combinação do tipo clientelista com as políticas distributivas, através de critérios políticopartidários o que garantiria uma eficiência eleitoral e ao mesmo tempo atender a demandas de uma clientela especifica. Ainda considerando que o ciclo político-eleitoral exerça papel decisivo à formulação e implementação de políticas públicas, a busca pela maximização de votos não é o único fator determinante, pressões eleitorais e grupos sociais também podem influenciar as decisões. O caso da política pública de economia solidária, que se enquadra neste tipo de política, e que apenas foi institucionalizada conforme Novaes; Lima (2007) por pressão do movimento de economia solidária. 


\section{Um panorama da política pública de economia solidária implementada no Brasil.}

Mais de trinta anos passaram-se do ressurgimento da economia solidária no Brasil e de ter-se tornado uma alternativa para o enfrentamento da crise do emprego estrutural, principalmente na década de 1990, quando ganha destaque. A notoriedade atingida ao longo do tempo, fez com que em 2003, com a mudança ocorrida na chefia do Estado brasileiro, a questão do trabalho tenha sido interpretada pelo ponto vista do novo governo, fazendo com o problema tenha ganhado o "status" de problema público e, nesta perspectiva, a economia solidária foi incluída na agenda de políticas públicas.

A pouco se apresentou a existência de pressão do movimento de economia solidária articulada pelo FBES (Fórum Brasileiro de Economia Solidária) que, em sua terceira edição, aponta para criação de um mecanismo que trate de uma política pública nacional de fomento economia solidária. Toda a articulação traduziu-se em uma carta construída durante o II Fórum Social Mundial que aconteceu na cidade de Porto Alegre no ano de 2002 e foi destinada ao recém-eleito (Lula) chefe do Estado brasileiro, reivindicando a criação de um espaço institucional a nível nacional que se constituísse como produtor das ações governamentais voltadas à economia solidária. Diante disto o governo cria o espaço institucional, que se trata da SENAES (Secretaria Nacional de Economia Solidária), sendo este o marco da institucionalização da economia solidária no Brasil.

A SENAES é criada para suprir a demanda que foi gerada durante os anos 1990, com desenvolvimento dos empreendimentos autogestionários, que com desemprego em alta os trabalhadores encontravam na economia solidária uma forma de garantir sua sobrevivência. Outros fatores de relevância são a informalidade que tem como causa a flexibilização do mundo trabalho, o desemprego em alta e as dificuldades existentes à formalização dos empreendimentos solidários. Nesta década o movimento de economia solidária consolida sua articulação iniciada ainda nos anos 1980 e ganha espaço na ação do poder público, como podemos observar na figura abaixo.

Abaixo na figura 2, é possível perceber a trajetória que o movimento de economia solidária percorreu até sua institucionalização em 2003. 


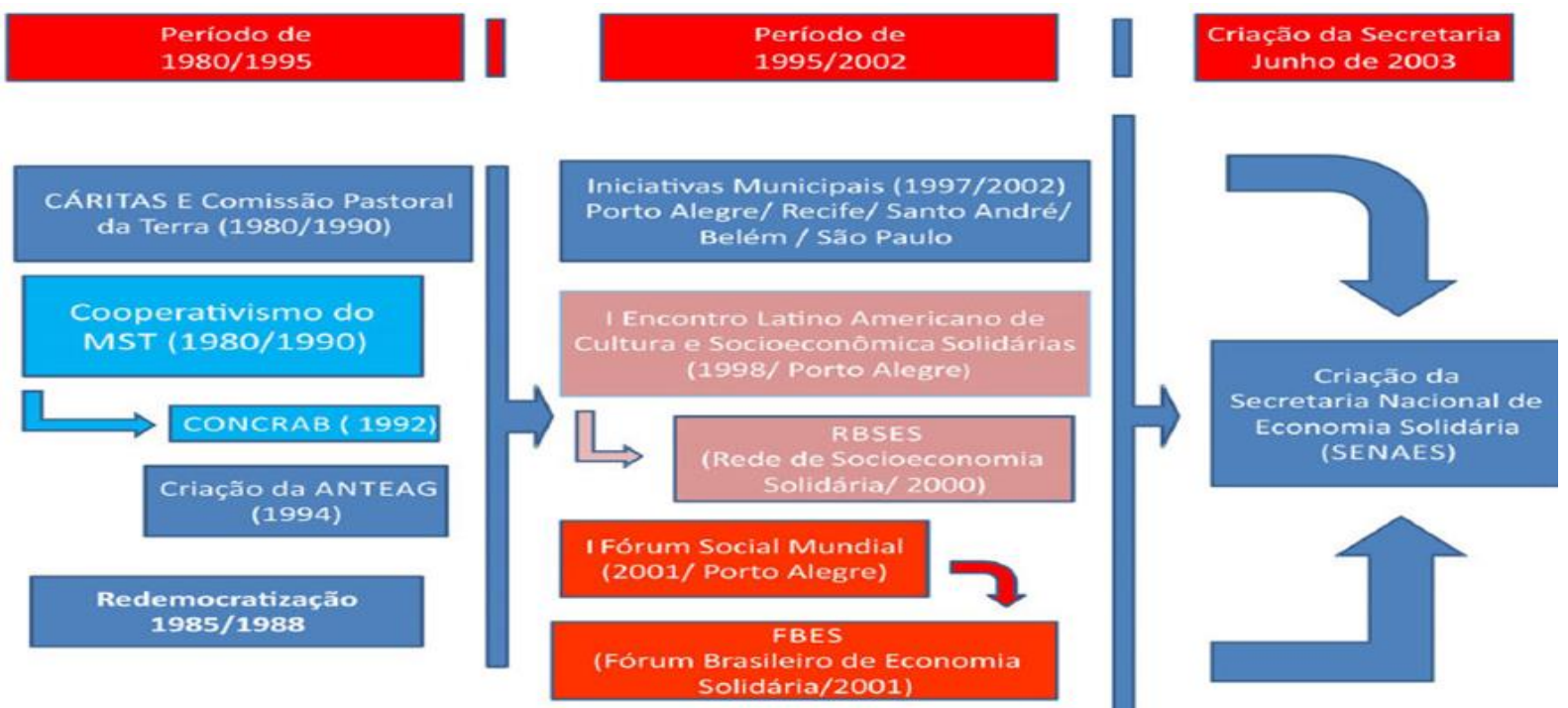

Figura 2 - Panorama geral do movimento de Economia Solidária no Brasil.

Fonte: Loks, 2014.

A secretaria foi criada no segundo semestre de 2003, o desenvolvimento de suas atividades inicialmente buscou fortalecer a economia solidária no país e sua consolidação institucional, por meio de sua integração com a sociedade civil e com as instituições governamentais de todas as esferas. Outra estratégia utilizada refere-se ao reconhecimento da economia solidária como um vetor de um novo modelo de desenvolvimento, orientado para o crescimento econômico sob outra lógica de organização do trabalho.

A consolidação institucional deu-se através do Programa Economia Solidária em Desenvolvimento, que foi adicionado nos Planos Plurianuais de 2004 - 2007 e 2008 - 2011. Este fato permitiu atender as demandas e as prioridades estabelecidas, destaca-se a realização de atividades formativas para gestores e servidores das mais distintas áreas do governo, no mesmo sentido a atividade foi realizada de forma descentralizada nos estados subnacionais para estimular a institucionalização em outras esferas de governo e disto acabou surgindo como efeito a Rede de Gestores de Políticas Públicas de Economia Solidária. Outro aspecto importante para consolidação se ancora na diretriz da existência da necessidade da criação de um marco que, adequadamente, reconheça as formas organizativas da economia solidária. No mesmo sentido foram estabelecidos canais de diálogo, para proporcionar o controle social das ações desenvolvidas e garantir a ampla participação da sociedade civil e suas organizações. Os canais criados compreendem a I Conferência Nacional de Economia Solidária (2006) e o Conselho Nacional de Economia Solidária. 
A decisão política de institucionalizar a economia solidária traduziu-se pelo Decreto $\mathrm{n}^{\circ}$ 4.764, de 24 de junho de 2003, que criou a SENAES e a submeteu a estrutura organizacional do Ministério do Trabalho e Emprego.

Segundo Alcântara (2005), ainda que existisse consenso dentro do movimento de economia solidária em relação à criação de um espaço institucional que tratasse da economia solidária, o mesmo consenso não se verificou quanto à alocação do espaço dentro do MTE.

O Ministério do Trabalho e Emprego historicamente deteve suas ações a resoluções de questões referentes ao trabalho assalariado. A economia solidária é claramente o estabelecimento de uma segunda linha de atuação, dentro de um espaço que não tem estreitamento algum com esta outra lógica de organização do trabalho.

A verificação da existência de duas linhas distintas de atuação política não é de exclusividade das políticas públicas direcionadas aos aspectos que englobam o mundo do trabalho. A agricultura é o outro caso em questão, só que diferentemente da economia solidária, a política para agricultura conta com dois ministérios, o Ministério da Agricultura, Pecuária e Abastecimento voltado ao agronegócio e Ministério do Desenvolvimento Agrário que direciona suas políticas para agricultura familiar. Além de ser uma linha de atuação nova, o fato de ser incorporada dentro de uma estrutura existente, trouxe dificuldades para a consolidação da nova política pública.

Mesmo diante das dificuldades de consolidar-se e da impossibilidade de elaborar diversos programas em decorrência dos processos de negociação internos e das resistências encaradas dentro do MTE e do próprio governo, o Programa Economia Solidária em Desenvolvimento foi a alternativa possível para executar a política. A partir de 2004, com orçamento próprio mesmo diante de dificuldades para a execução da política, pautaram a atuação da secretaria. Existia um conjunto de ações definidas em conjunto com as instâncias do Fórum Brasileiro de Economia Solidária (FBES), entre as ações estão a realização de um mapeamento nacional da economia solidária e apoio ao processo de comercialização dos produtos dos empreendimentos, a segunda estratégia diz respeito ao acolhimento de novas demandas.

Existiu necessidade de realizar adequações no programa para torná-lo compreensível para os setores de planejamento e controle. Esta necessidade deriva das dificuldades das ações da secretaria serem mensuradas e de alimentarem os sistemas de informação do governo, fatos que comprometeram a aprovação de seus orçamentos em virtude de não conseguir produzir informações. 
Em 2006, na I Conferência Nacional de Economia Solidária a política de economia solidária tem suas ações avaliadas em um espaço de participação e deliberação de seus rumos. Mesmo com a existência de dificuldades para execução da política, ressaltaram-se os avanços e a reafirmação das diretrizes para políticas construídas socialmente com os atores que compõem o movimento.

O acúmulo da experiência inicial da secretaria juntamente com os dados da economia solidária no Brasil advindos do primeiro mapeamento nacional, proporcionou a realização de um novo planejamento para o Plano Plurianual (PPA) 2008-2011, alicerçado pela participação popular, traduzidas nas resoluções da conferência nacional. Deste novo planejamento desdobraram-se quatro grandes eixos de atuação para o programa, que pretendem atender as necessidades do campo da economia solidária.

O primeiro eixo é composto pelas ações: I) formação de formadores/as, educadores/as e gestores/as públicos/as para atuação em economia solidária; II) fomento e assistência técnica aos empreendimentos da economia solidária e redes de cooperação; III) fomento a incubadora de economia solidária; IV) recuperação de empresas por trabalhadores organizados em autogestão. Neste eixo as ações visam propiciar aos empreendimentos da economia solidária acesso ao conhecimento para seu desenvolvimento.

A organização nacional da comercialização dos produtos e serviços dos empreendimentos econômicos solidários é o objetivo do segundo eixo.

O fomento as finanças solidárias com base em bancos comunitários e fundos solidários consistem no objeto de ação do terceiro eixo, que visa o financiamento e o acesso ao crédito aos empreendimentos.

No quarto eixo as diretrizes são orientadas para ações transversais com intuito de auxiliar a institucionalização da economia solidária nas demais esferas de governo e consolidar a política pública, para tanto se realizou: I) cadastro de empreendimentos e entidades de apoio para manutenção e ampliação do Sistema Nacional de Informações em Economia Solidária (SIES), originado a partir do primeiro mapeamento realizado pela secretaria; II) implantação de centros públicos; III) estimular a institucionalização da economia solidária e promover o desenvolvimento local.

Além dos quatro eixos de atuação, estabeleceram-se metas para o programa no PPA 2008 - 2011. A primeira meta é a ampliação do número de trabalhadores associados de 1.250.000 para 2.100.000, a segunda pretende reduzir o número de trabalhadores que ganham abaixo de um salário mínimo e a ampliação da participação da economia solidária no PIB de 
$0,59 \%$ para $1 \%$, ressalta-se que as metas foram à forma encontrada para mensurar a contribuição da economia solidária para inclusão social e a redução das desigualdades.

Entre os anos de 2003 e 2010, a SNAES apoiou 435 projetos da economia solidária diretamente ou indiretamente, através de parcerias. Diretamente foram 146 projetos, o restante contou com apoio da Fundação Banco do Brasil (FBB) que contribuiu com 175 projetos, da Financiadora de Estudos e Projetos (FINEP) e do Banco do Nordeste (BNB) que apoiou 50 projetos. Com relação aos valores investidos, totalizam $\mathrm{R} \$ 206.278 .341,41$ deste montante, a Secretaria Nacional de Economia Solidária, arcou com 63\% do total de recursos investidos e com $33 \%$ dos projetos apoiados diretamente no período. A seguir podemos observar como se distribuem os projetos apoiados por regiões.

\begin{tabular}{lcccc}
\hline \multicolumn{1}{c}{ Abrangência } & Projetos & $\%$ & R\$ & \% \\
\hline NORDESTE & 135 & $31 \%$ & $38.242 .988,60$ & $19 \%$ \\
SUDESTE & 99 & $23 \%$ & $40.847 .739,60$ & $20 \%$ \\
SUL & 73 & $17 \%$ & $23.624 .286,70$ & $11 \%$ \\
NORTE & 35 & $8 \%$ & $22.383 .075,20$ & $11 \%$ \\
CENTRO OESTE & 26 & $6 \%$ & $10.898 .380,70$ & $5 \%$ \\
NACIONAL & 67 & $15 \%$ & $70.281 .870,61$ & $34 \%$ \\
\hline \multicolumn{1}{c}{ TOTAL } & $\mathbf{4 3 5}$ & $\mathbf{1 0 0 \%}$ & $\mathbf{2 0 6 . 2 7 8 . 3 4 1 , 4 1}$ & $\mathbf{1 0 0 \%}$ \\
\hline
\end{tabular}

Tabela - 1 Distribuição dos projetos por regiões

Fonte: dados da SENAES - SOLTEC/UFRJ, 2012.

As políticas públicas de economia no Brasil são caracterizadas como políticas públicas distributivas, no conteúdo descrito encontram-se traços de outros tipos de políticas públicas, que dizem respeito às finalidades das políticas com lógicas de enfrentamento aos problemas sociais, as características presentes no caso apresentado são de políticas emancipatórias e de políticas estruturais.

\section{Conclusões}

A institucionalização da economia solidária é uma inovação no que tange a políticas de geração de trabalho e renda e de fomentar uma forma organizacional alternativa de produção. O novo governo que assumiu o comando do Estado brasileiro em 2003 manteve a política macroeconômica ortodoxa, porém conseguiu retomar a capacidade interventiva do Estado brasileiro, e escolheu como tema central de sua atuação combater a pobreza, com 
estabilidade econômica e geração de trabalho e renda, através de políticas focalizadas a clientelas específicas.

A política pública de economia solidária, além de democratizar o processo decisório ao deliberar suas diretrizes em conjunto com os movimentos sociais demonstrou uma capacidade de inserir suas políticas de forma transversal ampliando o leque de atuação. Nesta perspectiva, ao menos 21 ministérios executam políticas públicas voltadas à promoção da economia solidária, o que rompeu com a característica presente em outros espaços governamentais de implementar políticas de maneira segmentada e desconectadas. Isto rompeu também com um traço do sistema político brasileiro que, para a garantir a governabilidade, formam-se coalizões que têm visões diferentes no que se refere a políticas públicas.

Ainda que o projeto do movimento de economia solidária preconize uma transformação social profunda, através de um modelo de desenvolvimento baseado na propriedade coletiva e na autogestão, sua institucionalização pode representar para o governo uma oportunidade de tutelar o movimento, neutralizando-o e dando outro sentido para sua luta.

Mesmo que a compreensão de quem chefia a SENAES, aproxime-se da do movimento e diante do que foi descrito no texto, para outros setores do próprio governo, a política em evidência pode não passar de um amortizador de um conflito social ou um instrumento de inclusão transitório até que se alcance o emprego estrutural novamente. E talvez seja a razão para que a política de economia solidária não tenha alcançado à agenda com um ministério próprio, sendo alocada no MTE como uma segunda linha de atuação para geração de trabalho e renda.

\section{Referências}

ALCÂNTARA, Fernanda Henrique Cupertino. Economia Solidária: o dilema da institucionalização. São Paulo, Arte \& Ciência, 2005.

AZEVEDO, Francisco Fransualdo; ALIÓ, Maria Àngels; SILVA, Rafael Pereira da. Espacialidade da economia solidária no Brasil. Biblio 3W. Revista Bibliográfica de Geografía y Ciencias Sociales. [Em línea]. Barcelona: Universidad de Barcelona, 25 de enero de 2016, Vol. XXI, n 1.148. <http://www.ub.es/geocrit/b3w-1148.pdf>.

BAVARESCO, Agemir. A CRISE DO ESTADO-NAÇÃOE A TEORIA DA SOBERANIA EM HEGEL. Sociedade em Debate, Pelotas, 7(3):77-109, Dezembro/2001. 
BRASIL. Avanços e Desafios para as Políticas Públicas de Economia Solidária no Governo Federal - 2003/2010. UFRJ, Núcleo de Solidariedade Técnica - SOLTEC. Brasilia, junho de 2012.

BELLINI, Maria Isabel Barros; FALER, Camila Sussana (org.). Intersetorialidade e políticas sociais: interfaces e diálogos. In: Gleny Terezinha Duro Guimarães e Thiana Orth. Intersetorialidade e inclusão produtiva: um desafio para as políticas sociais. Porto Alegre: EDIPUCRS, 2014.

BONETI, Lindomar Wessler. Políticas Públicas por dentro. In: Estado, Sociedade Civil e Políticas Públicas. $3^{\text {a }}$ ed. Ijuí: Ed. Unijuí, 2011.

CORAGGIO, José Luis. La Presencia de la Economia Social y solidaria (ESS) y su Institucionalizacion em America Latina. Geneva, Switzerland: United Nations Research Institute for Social Development, 2013. Disponível em: http://www.unrisd.org/80256B42004CCC77/(httpInfoFiles)/6C316ABB64A13A7CC1257B 720034103A/\$file/JL\%20Coraggio.pdf

DINIZ, Eli. Globalização, Estado e desenvolvimento: dilemas do Brasil no novo milênio. Rio de Janeiro: Editora FGV, 2007.

GOHN, Maria da Glória. TEORIA DOS MOVIMENTOS SOCIAIS PARADIGMAS CLÁSSICOS E CONTEMPORÂNEOS. São Paulo: Edições Loyola, 1997.

Empoderamento e participação da comunidade em políticas sociais. Saúde soc. v.13 n.2 São Paulo maio/ago. 2004.

LOCKS, Pompilio. Formulação de agenda, políticas públicas e economia solidária no Brasil. Otra Economía, vol. 8, n. 14, enero-junio 2014. Disponível em: http://revistas.unisinos.br/index.php/otraeconomia/article/viewFile/otra.2014.814.05/4152

NOVAES, Henrique T.; LIMA FILHO, Paula A. Uma pedra protossocialista num colar prócapital financeiro. In: CONGRESSO INTERNACIONAL DE ECONOMIA SOLIDÁRIA, 4., 2007. Anais... São Paulo: Nesol-USP, 2007.

RUA, Maria das Graças; ROMANINI, Roberta. TIPOLOGIAS E TIPOS DE POLÍTICAS $P U ́ B L I C A S$.

Disponível

em:

nhttp://igepp.com.br/uploads/ebook/para_aprender_politicas_publicas__unidade_04.pdf

SANCHEZ, Fábio José Bechara. Autogestão, Economia Solidária e "invenções" democráticas na América Latina. $38^{\circ}$ ENCONTRO ANUAL DA ANPOCS: GT11 Democracia na América Latina: política, cultura, sociedade, 2014. Disponível em: http://www.anpocs.com/index.php/encontros/papers/38-encontro-anual-da-anpocs/gt-1/gt111/8914-autogestao-economia-solidaria-e-invencoes-democraticas-na-america-latina/file

SOUZA, Celina. Políticas públicas: uma revisão da literatura. Sociologias. vol. 8, n. 16, pp. 20-45, 2006. Disponível em: http://www.scielo.br/pdf/soc/n16/a03n16

SINGER, Paul. Introdução à Economia Solidária. $1^{\circ}$ Ed. - São Paulo, Editora Fundação Perseu Abrano, 2002. 
RELACult - Revista Latino-Americana de Estudos em Cultura e Sociedade

Revista Latinoamericana de Estudios en Cultura y Sociedad | Latin American Journal of Studies in Culture and Society V. 04, ed. especial, mai., 2018, artigo n ${ }^{\circ} 842$ | relacult.claec.org | e-ISSN: 2525-7870

. Uma utopia militante: Repensando o socialismo, - Petrópolis, Vozes, 1998. 